\title{
Development of a New Patient-Reported Medication Adherence Instrument: Concerns Influencing Medication Adherence
}

\author{
Sonal Ghura Mansukhani' \\ Elizabeth A MacLean ${ }^{2}$ \\ Laura L Manzey ${ }^{2}$ \\ Carl J Possidente ${ }^{2}$ \\ Joseph C Cappelleri iD ${ }^{2}$ \\ Linda S Deal ${ }^{2}$ \\ 'Patient Centered Outcomes Research, \\ Evidera, Waltham, Massachusetts, USA; \\ ${ }^{2}$ Medical Outcomes Specialists (EAM, \\ LLM, CJP); Patient Centered Outcome \\ Assessment (LSD); Biostatistics (JCC), \\ Pfizer Inc., New York, NY, USA
}

Purpose: The purpose of this research was to conceptualize and develop a tool for identifying persons who are, or are likely to be, non-adherent to medications prescribed by their healthcare provider(s) by identifying concerns that patients have regarding their treatments.

Patients and Methods: The target populations were persons diagnosed with atrial fibrillation or osteoarthritis, who were prescribed anticoagulants or over-the-counter or prescription pain medications, respectively. In this two-stage, multi-year, qualitative research study, relevant concepts were explored, confirmed and refined. The focus was on non-adherence due to active (thus potentially modifiable) patient decisions to forego taking medications as prescribed.

Results: The most common concerns among participants with atrial fibrillation were medication-related side effects and fear of bleeding. Participants with osteoarthritis were most concerned about short-term stomach problems and long-term kidney and liver side effects. The Concerns Influencing Medication Adherence (CIMA) instrument was developed based on these concerns and those identified in the literature. It is comprised of 16 items: a core set of 11 items potentially applicable to multiple disease states, 3 items specific to atrial fibrillation, and 2 items unique to osteoarthritis. The instrument is intended to be completed electronically, and publicly available for use in direct patient care in the United States or in population health management.

Conclusion: To our knowledge, this is the first instrument focused on medication adherence that includes documented details of patient input as recommended by the United States Food and Drug Administration guidance. Patient input is considered a key component of content validity. In this research, for example, the concerns that patients have regarding their treatments can be expected to have affected past medication adherence and can potentially impact future adherence. Although applicability outside atrial fibrillation or osteoarthritis was not assessed, the general items may be useful in assessing adherence in other chronic diseases.

Keywords: medication adherence, content validity, patient-reported outcome, atrial fibrillation, osteoarthritis

\section{Plain-Language Summary}

In general, patients who take their medications as prescribed have better health outcomes than those who do not. This was a two-stage, multi-year, qualitative research study in persons diagnosed with atrial fibrillation or osteoarthritis, who were prescribed blood thinners or pain medications, respectively. Our intent was to develop a questionnaire that might help identify persons who are, or are likely to, not take their medications the way their health provider told them to, by asking small groups of patients to voice their concerns about their medicines.
Correspondence: Linda S Deal Email Linda_Deal@yahoo.com 
The result of our research is the Concerns Influencing Medication Adherence (CIMA) questionnaire, a new patient-reported questionnaire made up of 16 questions: 11 that might apply to several diseases, 3 that are specific to atrial fibrillation, and 2 that are unique to osteoarthritis. The CIMA questionnaire is meant to be used by all types of healthcare professionals in many settings. It was created using techniques recommended by the United States Food and Drug Administration (FDA). This study did not answer how the questionnaire might work outside the United States or in persons with other chronic diseases, although the 11 general questions may be useful in that situation.

\section{Introduction}

Medication adherence, which is the extent to which patients take their medication as prescribed and in agreement with their healthcare provider, is an important determinant of the safety and effectiveness of their therapy. ${ }^{1}$ Optimal adherence is associated with improved health outcomes, such as reduced infectious disease transmission, reduced drug resistance, and lower healthcare utilization. ${ }^{2,3}$ As many as $69 \%$ of medication-related hospital admissions are due to poor adherence. ${ }^{4,5}$ In one recent study of 401 hospital readmissions, 26\% were found to be potentially preventable and medication related. Of these, $23.8 \%$ were associated with nonadherence due to patient choice. ${ }^{6}$

Chronic conditions are often associated with low medication adherence rates. ${ }^{1,3,7}$ It has been estimated that in the developed world only $50 \%$ of the persons with chronic disease take their medication as instructed. ${ }^{8,9}$ Adherence rates in developing countries are believed to be much lower. ${ }^{8}$ How well patients adhere to a particular regimen is a function of complex and dynamic behaviors influenced by an array of internal and external factors. ${ }^{1,8}$ Understanding the barriers and facilitators to optimal medication adherence is an important part of disease management.

A variety of instruments have been developed to collect information about medication adherence directly from patients. Some were developed for general use, others for use in specific conditions. One limitation of many currently available instruments is a lack of publicly available evidence of direct patient input and/or the use of past and future medication adherence mapping questions in developing the instrument content. This is now a key component to establishing content validity as described in the United States Food and Drug Administration's (FDA) 2009 Guidance on Patient-Reported Outcomes (PROs) ${ }^{10}$ and the FDA Patient-Focused Drug Development Guidance Series for Enhancing the Incorporation of the Patient's Voice in Medical Product Development and Regulatory Decision Making, which is in development. ${ }^{11}$ Additional limitations of many available instruments include lack of testing in a formal setting using electronic administration and presence of user fees or licensing requirements which may pose barriers to widespread use. This adherence assessment instrument is being developed with a goal of addressing these limitations.

The research described here focused on identifying concerns patients have regarding their treatment that may have affected past medication adherence patterns and could potentially impact future adherence. The target populations were persons diagnosed with atrial fibrillation (AFib) who were prescribed oral anticoagulants and persons diagnosed with osteoarthritis (OA) who were prescribed over-the-counter (OTC) or prescription medications for their OA pain. These 2 populations were chosen because of the potentially deleterious effects of non-adherence (stroke in the case of persons with AFib and potential use of opiates for pain control in the case of persons with OA) and because they are of interest to the study sponsor. The objectives of this research were to understand, from the perspective of persons living with AFib or OA, the concerns that influence their decisions to initially fill and then refill their medication; and, with that understanding, to develop a content-valid adherenceassessment tool for identifying persons who are, or are likely to be, non-adherent to their AFib or OA medications. For the purpose of this study, non-adherence was defined as failure to obtain the first prescribed refill and/or non-persistent after the first prescribed refill. We report here the evidence to support the development and content relevance of the Concerns Influencing Medication Adherence (CIMA) instrument.

\section{Materials and Methods}

Development of this new adherence assessment tool followed the Best Practices outlined in the FDA's 2009 PRO guidance. ${ }^{10}$ These include the use of literature reviews to understand past scientific insights on a given concept of interest; qualitative concept elicitation (CE) research to obtain direct patient input and point of view; and qualitative cognitive debriefing (CD) interviews to gauge respondent understanding of the instructions, item stems, categorical rating scales, and recall period. This was a two-stage, multi- 
year, qualitative research study that included content exploration and content confirmation and refinement (Figure 1).

\section{Stage I. Content Exploration}

Stage 1 consisted of a targeted literature review followed by a series of CE focus groups from which a pool of draft concepts was developed.

\section{Targeted Literature Review}

Targeted literature searches were conducted using MEDLINE $^{\circledR}$ and Embase ${ }^{\circledR}$ to identify peer-reviewed evidence relating to non-adherence to prescribed medications for AFib or OA, published in English between January 1, 2012, and October 1, 2018. The protocol for the search was developed in accordance with the Preferred Reporting Items for Systematic Reviews and Meta-Analyses (PRISMA) guidelines ${ }^{12,13}$ and the Guidance on the Conduct of Narrative Synthesis in Systematic Reviews. ${ }^{14}$ After identifying and screening for relevance to AFib, OA, and adherence, a thorough review of the publications was conducted. Eligible publications included those reporting on studies in adult patients with self- or clinician-reported AFib or OA that examined regulatory approved treatments and presented evidence on medication initiation, implementation, and discontinuation behaviors. The following study types were included: qualitative or quantitative observational studies, systematic reviews and/or meta-analyses, adherence-intervention research, qualitative clinical research, or analyses of real-world evidence data among adult patients with AFib or OA.

In addition to the articles identified from the search, the reference list of each article deemed eligible for full-text abstraction was examined for any pertinent literature cited before 2012. Abstract and article screening was performed in 3 levels of increasingly in-depth review: title and abstract, full text, and data extraction. Articles were selected for full-text abstraction according to the following prioritization (from highest to lowest priority):

- Original qualitative research describing patients' adherence value propositions (trade-offs between perceived benefits and risks), patients' subjective prioritization of their AFib or OA, or patientcentered and modifiable adherence drivers (eg, selfreported reasons for adherence or non-adherence).

- Original research that describes the development and/ or validation of adherence surveys or segmentation tools specific to AFib or OA or includes patients with AFib or OA.

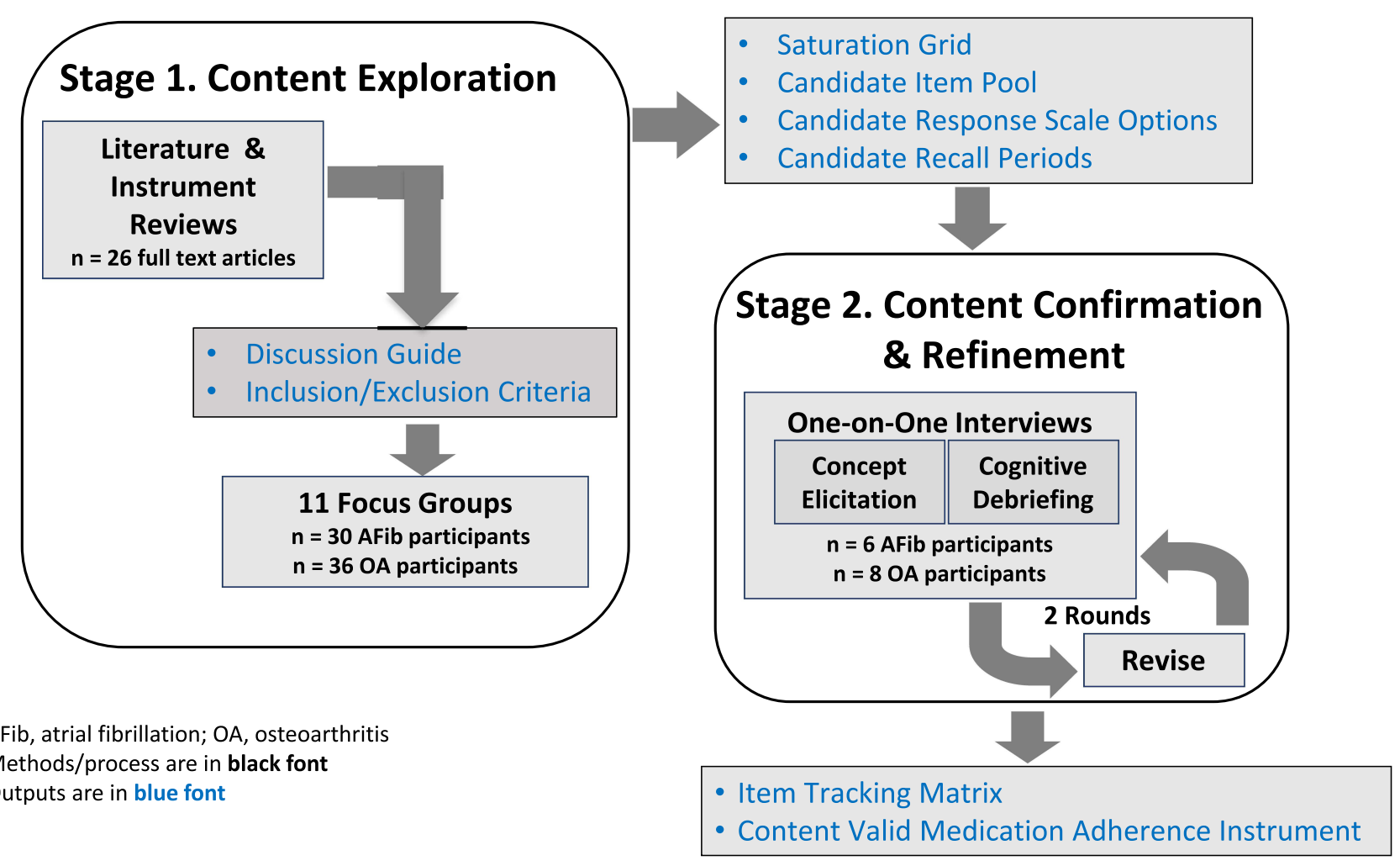

Figure I Schematic of the instrument development flow. 
- Narrative or systematic reviews, meta-analyses, or meta-ethnographies that focus on patient-centered and modifiable adherence drivers specific to AFib or OA.

- Original qualitative or quantitative research focusing on patient preferences concerning prescription medications for AFib or OA.

- Conference abstracts specific to medication adherence in AFib or OA.

- Publications reporting results only from administrative data (eg, pharmacy claims data that assess largely immutable drivers of non-adherence).

- For AFib, prioritization was given to publications that focus on direct-acting oral anticoagulants (DOACs) as opposed to warfarin.

The reviewers were not blind to the journal titles, study authors, or institutions. Reviewers resolved disagreements by discussion. The Principal Investigators adjudicated unresolved disagreements. The final list of articles deemed eligible for final abstraction ( $\mathrm{n}=13$ each for $\mathrm{AFib}^{15-27}$ and $\mathrm{OA}^{28-40}$ ) was submitted to the study team for final review and approval.

A thematic analysis ${ }^{41}$ was performed to assess the extracted data. This analysis involved reading then rereading the extracted data to identify themes relating to initiation, implementation, and discontinuation of treatment regimens from the patient perspective, as well as caregiver and clinician perspectives, if available. When multiple perspectives were available, the results were compared to identify similarities and differences. Thematic analysis was conducted in 4 steps: in-depth reading of each article, abstraction of relevant findings, comparing and contrasting themes across AFib and OA separately, and final synthesis of data-driven themes. The abstracted data were assigned discrete conceptual labels and classified into descriptive qualitative themes. Codes were added through iterative review of the abstracted articles until a final coding schema emerged. The analysis was developed inductively (ie, directed by data content), whereby themes were developed through constant comparison of the similarities and differences in the abstracted data from the articles; both supportive and disconfirming evidence of the themes were identified.

\section{Concept Elicitation Focus Groups}

During November and December 2018, persons with AFib or OA were recruited by an experienced qualitative research recruitment firm to attend in-person focus groups at sites in Los Angeles, California and Philadelphia, Pennsylvania, United States (US). The objective was to understand patientcentered reasons for medication adherence and non-adherence. Discussion focused on the participants' self-reported reasons for adherence or non-adherence to medications prescribed for their AFib or OA, including facilitators and barriers to optimal medication adherence, the beliefs and attitudes that influence their medication-taking, their knowledge and understanding about their disease and their prescription medications, and how aspects of the doctor-patient relationship influence their adherence.

A maximum of 12 focus groups (6 each for AFib and OA) was planned with approximately 80 participants in total. Interested participants were screened by telephone using a standardized script to evaluate eligibility and ensure recruitment targets were met. The focus groups were expected to last 1.5 hours and were conducted in sequence; saturation, the point at which no new themes emerge, was assessed sequentially. The groups were separated by gender to enhance open conversation and minimize biases associated with gender differentials in conversational dynamics. ${ }^{42}$ Semi-structured discussion guides were used to conduct the groups and all group discussions were audio-taped and transcribed.

Both the discussion guide and the transcript for each focus-group were reviewed to develop an a priori coding dictionary to capture important concepts of interest related to medication adherence, non-adherence, and medicationimplementation errors raised by the participants. Transcripts were coded by trained coders to highlight participant responses to scripted probes, as well as any themes that emerged. Concept saturation was tracked on an ongoing basis following analysis of each focus group, thus enabling ongoing assessment and slight revision in content as the focus groups proceeded. At the end of the concept elicitation phase, the research team met to determine which concepts would be represented in the instrument. The decision was based on the extent to which a concept was viewed as modifiable and actionable for affecting medication adherence.

\section{Stage 2. Content Confirmation and Refinement}

The objective of Stage 2 was to finalize a set of contentvalid items representing the concerns that influence medication adherence from the perspective of individuals 
living with AFib or OA. This was achieved through oneon-one hybrid qualitative interviews that began with a very brief CE section to solicit feedback on the participants' experiences with taking their prescribed medications, followed by a very lengthy and detailed CD section designed to assess whether the draft questions were relevant, comprehensive, and understandable to the participants.

\section{One-on-One Interviews}

The goal was to screen and recruit 16 adults with AFib or OA ( 8 for each condition) for one-on-one, in-person, qualitative interviews. The 1.5-hour interviews were conducted by senior staff at two locations (Philadelphia, Pennsylvania and Boston, Massachusetts, US) using semi-structured, qualitative interview guides specific to AFib or OA and the draft medication adherence instrument. The interviews were recorded and transcribed by a third-party vendor. After half of the interviews were conducted, minor modifications were made to the draft items (ie, adding parentheses to one question, changing the order of a set of questions, and correcting a small handful of typographical errors and numbering sequences) for testing in the remaining interviews.

During the interviews, participants completed either the AFib or OA draft medication adherence instrument by themselves, after which they were asked to reflect on each question using the think-aloud approach. ${ }^{43}$ To confirm that the content was relevant and comprehensive, participants were asked to discuss any concepts they felt were missing when considering adherence to their medication. Then they were asked what each question meant to them, why they chose the response option they did, and what possible scenarios might cause them to choose other response options. To test the word question stems and address the different phrasing of the questions, participants were asked how each stem differed in meaning and why they preferred one wording over the others. Concepts that could be combined were also discussed. Further, participants were asked to reflect on various response scale constructs, eg, level of worry, level of concern, etc., to ensure that the response scale construct was reflective of the intention of the item's stem. Finally, the interviews explored comprehension that the recall period for responding to the items was current, ie, right now, in this moment.

\section{Research Participants}

Across both stages of the research, efforts were made to recruit individuals who were diverse with respect to duration and severity of disease, education, race or ethnicity, socioeconomic status, healthcare insurance type, and adherence-status. For Stage 1, participants with AFib were required to be currently taking or recently (past 12 months) non-persistent to a DOAC (60\% quota) and/or a vitamin-K antagonist (VKA; 40\% quota). The requirements for Stage 2 were similar except that individuals taking a VKA were not eligible to participate. The requirements were the same for both Stages in the OA group: ie, participants were required to be currently taking or to have taken medication for $\mathrm{OA}$ in the past 12 months. This included prescription or OTC nonsteroidal antiinflammatory drugs (NSAIDS), narcotic pain relievers, combination medicines with acetaminophen, tramadol, injectable steroids, or prescription topical treatments, referred to collectively hereafter as OA medications. Further, OA participants had to report that their worst OA pain in the past month was $\mathrm{a} \geq 5$ on an 11-point scale where 0 means "No pain" and 10 means "Worst pain you can imagine".

All participants were required to be able to read, speak, and understand English sufficiently to complete the assessments and to be willing and able to attend an in-person interview session, complete questionnaires, and provide written informed consent. Consent to being audio recorded was also required for participation. Presence of a major health problem that would interfere with participation in an in-person interview; hospitalization for any reason at time of screening; major surgery within 8 weeks prior to screening; presence of any other clinically relevant and/or serious chronic medical condition which, in the opinion of the sponsor's research team and/or investigator, would interfere with completion of the research study procedures, and refusal to be observed by the sponsor from a different room were also causes for exclusion. The following additional restrictions were in place: focus group participants were not eligible to participate in the $\mathrm{CE}$ one-on-one interviews; persons involved as a research participant for the recruiting agency $>3$ times in the last 12 months could not participate in either the focus groups or the one-on-one interviews. Key inclusion criteria for both stages of the research are shown in Table 1.

\section{Data Analysis}

Audio recordings and interviewer notes from the one-on-one interviews were used to analyze participants' responses. A thematic, content-analysis approach ${ }^{44}$ was used to analyze data from the transcripts obtained from the focus groups and one-one-one interviews. These narrative data were entered 
Table I Inclusion Criteria for Both Stages of the Research

\begin{tabular}{|l|l|l|l|}
\hline \multicolumn{2}{|c|}{ Stage I. Content Exploration } & \multicolumn{1}{c|}{ Stage 2. Content Confirmation and Refinement } \\
\hline \multicolumn{1}{|c|}{ AFib } & \multicolumn{1}{|c|}{ OA } & \multicolumn{1}{c|}{ AFib } \\
\hline Self-report of a physician diagnosis of AFib & $\begin{array}{l}\text { Self-report of } \\
\text { a physician diagnosis of } \\
\text { OA }\end{array}$ & $\begin{array}{l}\text { Self-report of } \\
\text { a physician diagnosis } \\
\text { of AFib }\end{array}$ & $\begin{array}{l}\text { Self-report of a physician diagnosis of OA and } \\
\text { experience of OA in the hip or knee in the } \\
\text { past month AND currently experiencing OA } \\
\text { pain }>5 \text { on a 10-point scale }\end{array}$ \\
\hline Age $\geq 18$ years at screening & $\begin{array}{l}\text { Age } \geq 30 \text { years at } \\
\text { screening }\end{array}$ & $\begin{array}{l}\text { Age } \geq 18 \text { years at } \\
\text { screening }\end{array}$ & Age $\geq 30$ years at screening \\
\hline $\begin{array}{l}\text { Self-report of currently taking or recently } \\
\text { (past I2 months) non-persistent to DOACs } \\
\text { (target } 60 \% \text { of participants) or VKAs (target } \\
40 \% \text { of participants) }\end{array}$ & $\begin{array}{l}\text { Self-report of currently } \\
\text { taking or ever taken } \\
\text { a prescription } \\
\text { medication for OA }{ }^{c}\end{array}$ & $\begin{array}{l}\text { Self-report of } \\
\text { currently taking or } \\
\text { ever having taken } \\
\text { a DOAC for AFib }\end{array}$ & $\begin{array}{l}\text { Self-report of currently taking or ever having } \\
\text { takescription medication for OA }\end{array}$ \\
\hline $\begin{array}{l}\text { Self-reported recent (past I2 months) medication non-adherence (target } \\
\geq 50 \% \text { of participants) or medication implementation errors once in the } \\
\text { past week or } \geq 3 \text { times in the past month (target } \geq 25 \% \text { of participants) }\end{array}$ & $\begin{array}{l}\text { Self-reported recent (past I2 months) medication non-adherence or } \\
\text { medication-implementation errors once in the past week or } \geq 3 \text { times in } \\
\text { the past month }{ }^{\mathrm{d}}\end{array}$ \\
\hline
\end{tabular}

Notes: ${ }^{a}$ In response to the question: "Over the past month or 30 days, how would you rate your worst level of OA pain in your knee or hip on a scale of 0-10, where zero means No pain and 10 means Worst pain you can imagine? ${ }^{b}$ Apixaban, betrixaban, dabigatran, edoxaban, or rivaroxaban. ${ }^{\mathrm{C} O A}$ medications were described to potential participants as follows: analgesics, narcotic analgesics, nonsteroidal anti-inflammatory drugs (NSAIDs), Cox-2 inhibitors, injectable steroids (also known as glucocorticoids or steroids), or prescription topical treatment (eg, creams, gels, or ointments). ${ }^{\mathrm{d}}$ Non-adherence: failure to obtain the first prescribed refill and/or intentional non-persistence after the first prescribed refill. Medical implementation error: forgetfulness (especially evening doses), carelessness, self-initiated dose titration, or self-initiated "drug holidays".

Abbreviations: AFib, atrial fibrillation; DOAC, direct-acting oral anticoagulant; OA, osteoarthritis; VKA, vitamin-K antagonist.

into and analyzed by ATLAS.ti ${ }^{45}$ to organize the data. Descriptive statistics were used to summarize the quantitative data, which were entered into DataFax, an FDA Title 21 Code of Federal Regulations Part 11 compliant system that provides a time-stamped electronic audit trail for the creation, modification, or deletion of electronic data. Quantitative and sociodemographic data were analyzed using SAS version 9.4. Descriptive statistics were used to summarize participant demographics and clinical characteristics. All participants who provided consent and fulfilled the research study entry criteria were included in the analyses.

\section{Protection of Participant Rights}

This study was conducted in accordance with the Declaration of Helsinki. All parts of this research protocol were approved by a central Institutional Review Board (IRB: Advarra, 6940 Columbia Gateway Drive, Suite 110, Columbia, MD 21046, USA) prior to study initiation. All participants provided written informed consent prior to participation. Participants were informed that participation in the research was voluntary, and they could refuse to participate or withdraw at any time without penalty and without giving up any benefits to which they were otherwise entitled. All participant data were de-identified. Participants received nominal remuneration for their time.

\section{Results}

\section{Stage I. Content Exploration Targeted Literature Review}

The AFib literature search identified 591 unique citations for screening; 483 were deemed ineligible, the majority because they reported on clinical trials (58\%). The remaining 108 were reviewed by the research team for final determination of which would be subject to full-text extraction. Thirteen publications were selected for full-text extraction. Research methods in these studies were as follows: mixed-method research $(n=5)$, qualitative focus groups $(\mathrm{n}=4)$, one-on-one semi-structured interviews $(n=2)$, and literature review $(n=2)$. Two of the mixed-method studies were specific to PRO development for AFib.

The OA literature search identified 491 unique citations for screening; during the first review, 427 were deemed ineligible as they did not match the inclusion criteria. The top reason for abstract ineligibility was study type being clinical trial (68\%). A second screening identified 51 duplicates among the remaining 64 abstracts (eg, multiple conference presentations or publications from the same study), leaving 13 unique articles for full-text extraction. Research methods in the selected studies included the following: qualitative focus groups $(\mathrm{n}=1)$, qualitative, semi-structured 
interviews $(n=4)$, survey research $(n=6)$, mixed-method research $(\mathrm{n}=1)$, and meta-ethnography $(\mathrm{n}=1)$.

In total, 26 themes that influence medication adherence were identified from the targeted literature search; 10 shared between AFib and OA; 9 unique to AFib; and 7 unique to OA (Figure 2).

The themes identified in the targeted literature review were used to draft a focus group discussion guide for use across AFib and OA. The Proximal-Distal Continuum of Adherence Drivers ${ }^{46}$ was used as a conceptual framework to apply the findings from the TLR to the qualitative guides. The continuum asserts that some adherence determinants are nearer or closer to patients' medication-taking decisions (proximal) while others are more removed from patients' adherence decisions (distal). This continuum was specifically studied and populated with respect to the literature extracted from AFib and OA. Figures 3 and 4 show how the extracted reasons for adherence/non-adherence from the TLR in AFib and OA were applied to present a framework of the proximal-distal continuum in each of the diseases. The guides were developed using the content derived from these figures and addressed seven general topics: patient knowledge, unmet information needs, and experience of conflicting medical information; perceived medication concerns; perceived need for medications; perceived medication affordability; aspects of the medication regimen; aspects of the doctor-patient relationship; practical adherence facilitators.

\section{Research Participants}

Participants in both stages of this research were diverse with respect to their demographic (Table 2) and clinical characteristics (Table 3).

\section{Focus Group Results}

Eleven focus groups were conducted: 5 for AFib (2 in Los Angeles, California and 3 in Philadelphia, Pennsylvania, US) and 6 for OA (3 each in Los Angeles and Philadelphia). There were 66 participants in total (30 in the AFib groups and 36 in the OA groups). The demographic characteristics of these individuals can be found in Table 2.

\section{AFib Participant Perspectives}

High-level insights were remarkably similar between the two geographic locations. Saturation was achieved in these five focus groups.

All participants understood the clinical nature of AFib, had a good understanding of why they were taking oral anticoagulants, and generally understood that they would need to take their medication for the rest of their lives. Overall, participants adhered to their oral anticoagulant regimen. Intentional medication non-adherence was rarely reported. The most common reason for unintentional nonadherence was forgetting doses $(56.7 \% ; n=17 / 30)$, which was reported as a particular challenge with twice daily medications. The majority $(76.7 \% ; n=23 / 30)$ of participants expressed that they were adherent to their AFib therapy most of the time. Only a few expressed that they were $100 \%$ diligent and had never missed a dose, mostly because of the perceived seriousness of the disease.

All participants said that, whenever they received a new prescription for their oral anticoagulants, they filled it (primary adherence); however, subsequent discussion showed that at least 5 participants mentioned they did not refill all prescriptions. The most common reason for

\begin{tabular}{|c|c|c|}
\hline AFib & Shared & OA \\
\hline $\begin{array}{l}\text { INR testing/monitoring } \\
\text { Medication routines } \\
\text { Food interactions/dietary restrictions } \\
\text { VKA vs DOAC INR monitoring } \\
\text { DOAC antidote } \\
\text { Alcohol interactions } \\
\text { Forgetfulness } \\
\text { Carelessness } \\
\text { Drug-drug interactions }\end{array}$ & $\begin{array}{c}\text { Patient knowledge } \\
\text { Side-effects } \\
\text { Dosing regimen } \\
\text { Social support } \\
\text { Doctor-patient relationship } \\
\text { Perceived drug effectiveness } \\
\text { Financial constraints } \\
\text { Perceived need for medications } \\
\text { Conflicting medical information } \\
\text { Practical medication reminders }\end{array}$ & $\begin{array}{c}\text { Fear of dependence } \\
\text { Other suboptimal medication beliefs } \\
\text { PRN dosage rationalization } \\
\text { Pain symptoms } \\
\text { Mechanism/speed of action } \\
\text { Nutraceuticals } \\
\text { Work-related stigma }\end{array}$ \\
\hline
\end{tabular}

DOAC, direct oral anticoagulant; INR, international normalized ratio; PRN, pro re nata (as needed); VKA, vitamin-K antagonist

Figure 2 Shared and unique adherence drivers. 


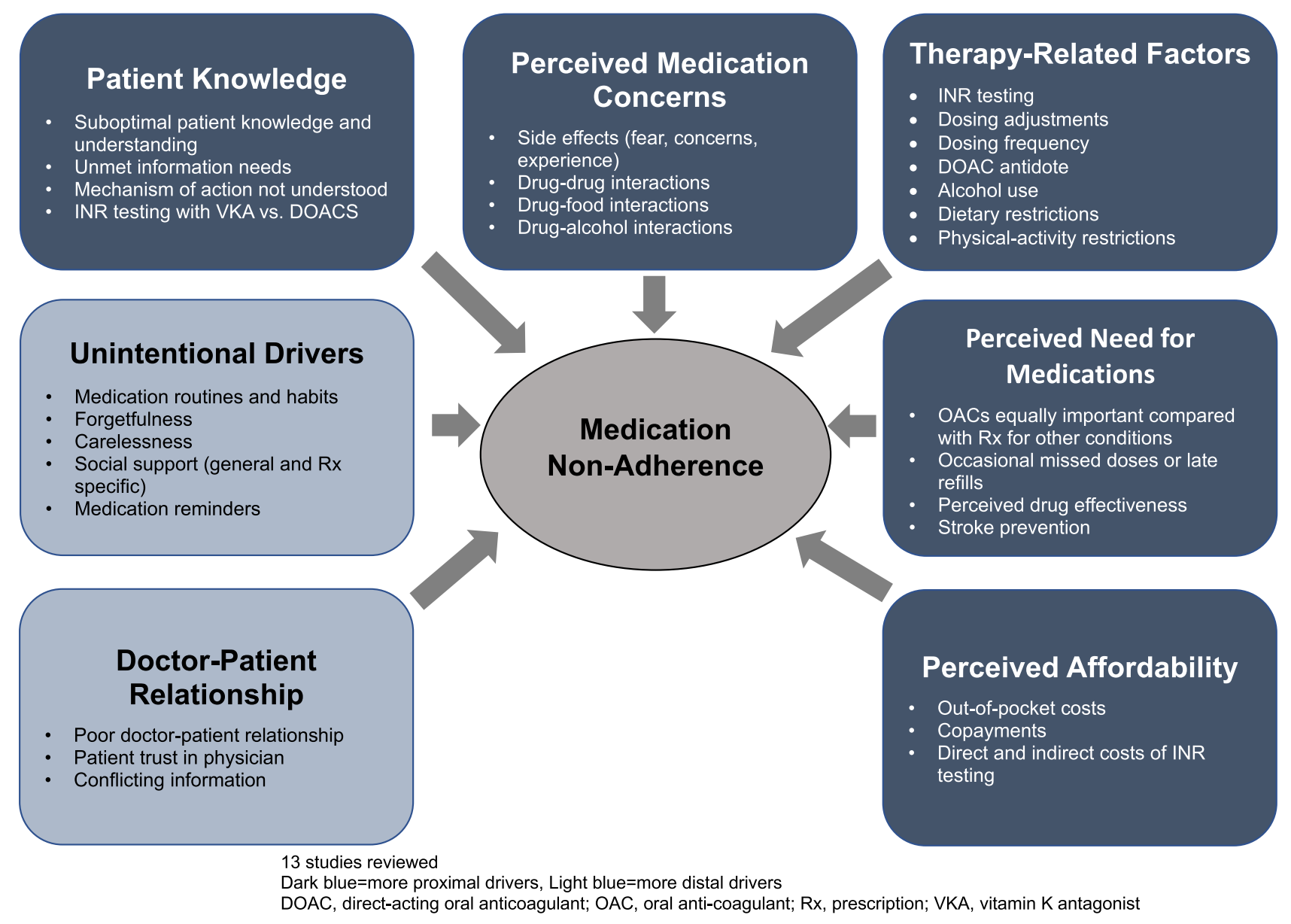

Figure 3 Elements of the proximal-distal continuum of adherence drivers specific to AFib.

not refilling a prescription was medication side-effects $(16.7 \% ; n=5 / 30)$.

Most participants felt very independent and did not need or want any social or technological support to remind them to take their medications. They used pill boxes and compartmentalized medicine trays to remind themselves to take their medications.

On being asked how they prioritize AFib compared with other chronic diseases they have, AFib appeared to be among the highest in importance. There was a sense of fear toward AFib, as it affects their heart and could be fatal. Other chronic diseases the participants had that ranked higher than AFib were hypertension, because "hypertension leads to AFib," heart failure, hypertrophic cardiomyopathy, leukemia, sleep apnea, and depression. Other diseases, such as diabetes, OA, rheumatoid arthritis, and peripheral neuropathy, were being managed with medications consistently, and the participants felt their conditions were under control.

The top two concerns for participants were medicationrelated side effects and the fear of "bleeding to death" (both 46.7\%; n=14/30). Participants were also concerned about internal bleeding and bruising as side effects of their medications and wanted to know the long-term side effects of the DOACs they were taking. About half of the participants also expressed concern that they were not sure if their AFib drug was working and felt the need to know more about monitoring their disease and drugs.

Five participants $(16.7 \% ; \mathrm{n}=5 / 30)$ indicated they were concerned about developing resistance to their current medication and being in a situation where the medication would no longer work for them. Two participants mentioned that they were concerned about dependency and addiction to their AFib drugs $(6.7 \% ; n=2 / 30)$ and expressed that long-term usage may make their bodies dependent on these drugs for clotting, thereby interfering with natural clotting. Affordability of medications was a concern for about onequarter of participants $(26.7 \% ; n=8 / 30)$.

A majority of participants $(66.7 \% ; n=20 / 30)$ expressed trust in their doctors and indicated that they have a positive relationship with them. Almost all participants (93.3\%; 


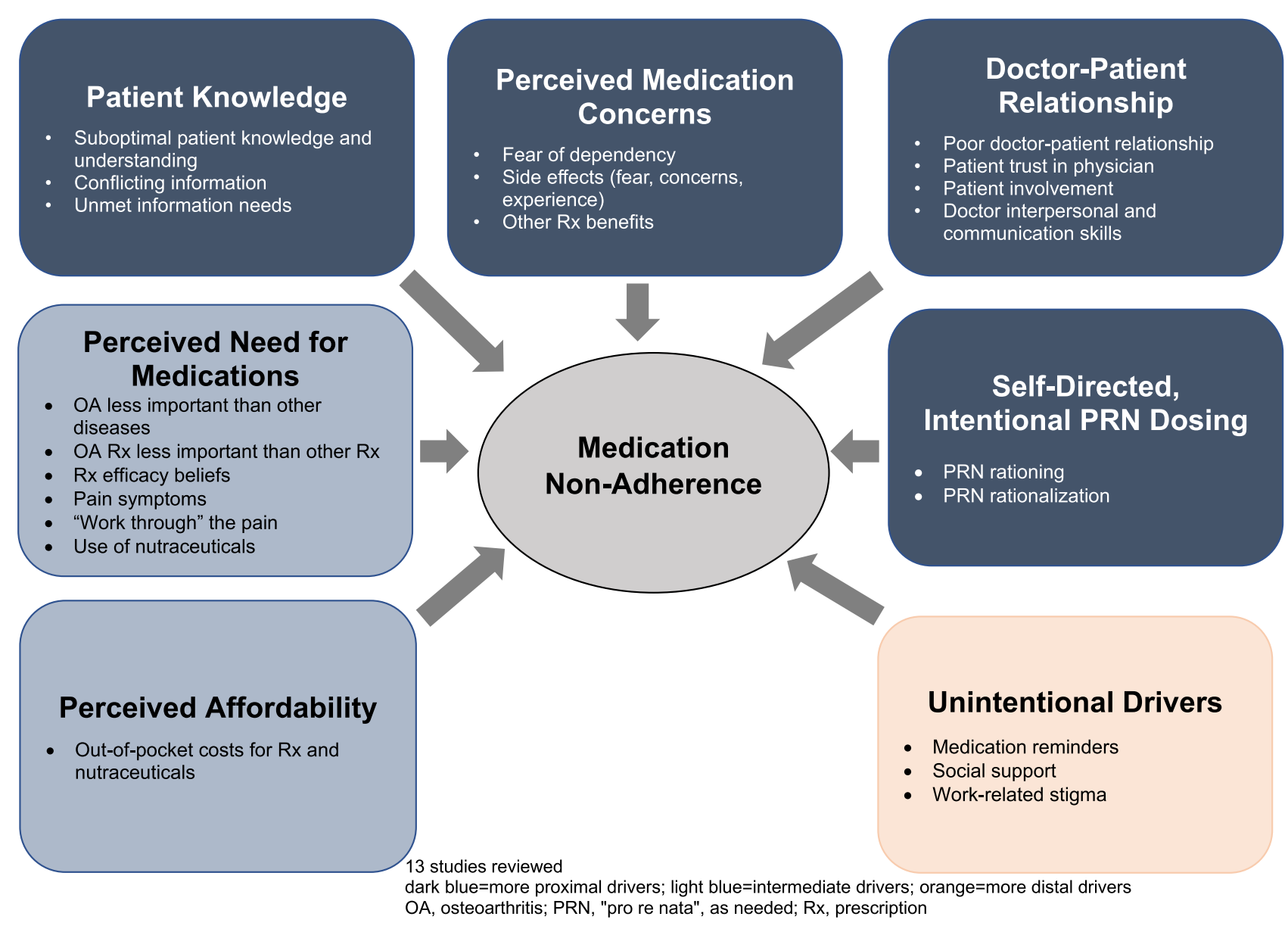

Figure 4 Elements of the proximal-distal continuum of adherence drivers specific to OA.

$\mathrm{n}=28 / 30$ ) had heard of nutraceuticals, herbal, and other OTC therapies for AFib.

\section{OA Participant Perspectives}

As with the AFib sample, high-level insights were similar between the two geographic locations, and saturation was achieved in six focus groups.

Pain was the most common symptom among the 36 OA participants. On an 11-point scale of 0 to 10 , with 10 being the most severe, most participants in one focus group described their average pain levels on a normal day to be between 3 and 6 inclusive during the day and worse at night. Most of the participants admitted to being nonadherent to their OA prescription medications most of the time. Although they realized the importance of their medications, they were not adherent to the recommended dosing, because they felt they could manage their pain with non-prescription resources such as icing or taking OTC products. When it came to pain management, there was a sense of "stretching out the prescription" or "fighting through (the pain)."

The majority of OA participants took their OA prescription medications PRN (pro re nata; as needed). Some spoke of "shuffling" the bolus of all their prescription medications, meaning that in some situations they might prioritize one medication over another. Participants who shuffled their medications all stated they made that decision on their own.

Only two participants stated they were $100 \%$ adherent with their OA prescription medications. Almost all participants $(92 \%)$ said that when they received a new prescription for their OA, they filled it; however, they almost all admitted to being nonadherent to filling the first refill at some point in time. Most of the participants $(86 \%$; $n=31 / 36$ ) who chose not to get their first refill noted that the medication was not effective in reducing their pain or that its effects wore off. Other reasons for not refilling their prescription included fear of or experience of side effects, ie, gastrointestinal disturbances and insomnia 
Table 2 Demographic Characteristics

\begin{tabular}{|c|c|c|c|c|}
\hline \multirow[b]{2}{*}{ Demographic Characteristics } & \multicolumn{2}{|c|}{ Stage I. Content Exploration } & \multicolumn{2}{|c|}{$\begin{array}{l}\text { Stage 2. Content Confirmation anc } \\
\text { Refinement }\end{array}$} \\
\hline & AFib $(\mathbf{N}=30)$ & OA $(N=36)$ & AFib $(\mathbf{N}=6)$ & $\mathrm{OA}(\mathrm{N}=8)$ \\
\hline \multicolumn{5}{|l|}{ Age (Years) } \\
\hline Mean (SD) & $63.03(9.64)$ & $60.9(9.37)$ & $68.3(10.75)$ & $61.0(11.88)$ \\
\hline \multicolumn{5}{|l|}{ Years since diagnosis } \\
\hline Mean, years (range) & $8.76(I-40)$ & $12.1(1-30)$ & $9.2(4-15)$ & $11.6(2-30)$ \\
\hline \multicolumn{5}{|l|}{ Gender, n (\%) } \\
\hline Male & $12(40.0)$ & $17(47.2)$ & $5(83.3)$ & $4(50.0)$ \\
\hline Female & $18(60.0)$ & $19(52.8)$ & I (I6.7) & $4(50.0)$ \\
\hline \multicolumn{5}{|l|}{ Ethnicity, n (\%) } \\
\hline Not Hispanic or Latino & $24(80.0)$ & $32(88.9)$ & $5(83.3)$ & $8(100)$ \\
\hline Hispanic or Latino & $4(13.3)$ & $2(5.6)$ & I (I6.7) & $0(0.0)$ \\
\hline Missing & $2(5.6)$ & $2(5.6)$ & $0(0.0)$ & $0(0.0)$ \\
\hline \multicolumn{5}{|l|}{ Racial Background, n (\%) ${ }^{a}$} \\
\hline Black or African American & $7(23.3)$ & $16(44.4)$ & $0(0.0)$ & $2(25.0)$ \\
\hline White & $22(73.3)$ & $220(55.6)$ & $5(83.3)$ & $6(75.0)$ \\
\hline Other ${ }^{\mathbf{b}}$ & I (3.3) & $\mathrm{I}(2.8)$ & I (16.7) & $0(0.0)$ \\
\hline \multicolumn{5}{|l|}{ Relationship Status, n (\%) } \\
\hline Married/living with significant other & $16(53.3)$ & $14(38.9)$ & $5(83.3)$ & $2(25.0)$ \\
\hline Widowed & I (3.3) & $3(8.3$ & $0(0.0)$ & $0(0.0)$ \\
\hline Divorced/separated & $8(26.7)$ & II (30.6) & I (16.7) & $2(25.0)$ \\
\hline Single (never married) & $5(16.7)$ & $8(22.2)$ & $0(0.0)$ & $4(50.0)$ \\
\hline \multicolumn{5}{|l|}{ Domestic Living Status, n (\%) } \\
\hline Own home, apartment, or condominium & $30(100.0)$ & $34(94.4)$ & $6(100)$ & $8(100)$ \\
\hline Other ${ }^{\mathrm{c}}$ & $0(0.0)$ & $2(5.6)$ & $0(0.0)$ & $0(0.0)$ \\
\hline \multicolumn{5}{|l|}{ Employment Status, $\mathbf{n}(\%)^{c}$} \\
\hline Employed full-time & $9(30.0)$ & $16(44.4)$ & $2(33.3)$ & $5(62.5)$ \\
\hline Employed part-time & $4(13.3)$ & $5(13.9)$ & I (I6.7) & I (I2.5) \\
\hline Unemployed & $0(0.0)$ & I (2.8) & $0(0.0)$ & $0(0.0)$ \\
\hline Retired & $12(40.0)$ & $14(38.9)$ & $3(50.0)$ & $2(25.0)$ \\
\hline Disabled & $4(13.3)$ & I (2.8) & $0(0.0)$ & $0(0.0)$ \\
\hline Self-employed & $2(6.7)$ & I (2.8) & I (I6.7) & $0(0.0)$ \\
\hline \multicolumn{5}{|l|}{ Highest Level of Education, $\mathbf{n}(\%)^{c}$} \\
\hline High school/GED & $3(10.0)$ & $2(5.6)$ & $2(33.3)$ & $0(0.0)$ \\
\hline Some college but no degree & $8(26.7)$ & II (30.6) & $0(0.0)$ & $2(25.0)$ \\
\hline 2-year degree, vocational/technical/trade school & $6(20.0)$ & $4(11.1)$ & I (I6.7) & $0(0.0)$ \\
\hline 4-year university/college degree & $8(26.7)$ & $13(36.1)$ & I (I6.7) & $4(50.0)$ \\
\hline Advanced degree & $5(16.7)$ & $6(16.7)$ & $3(50.0)$ & $2(25.0)$ \\
\hline \multicolumn{5}{|l|}{ Health Insurance, $n(\%)^{a}$} \\
\hline Commercial or employer-based health insurance & $14(46.7)$ & $17(47.2)$ & $2(33.3)$ & $5(62.5)$ \\
\hline Medicaid & $3(10.0)$ & $7(19.4)$ & I (I6.7) & $0(0.0)$ \\
\hline Medicare & $15(50.0)$ & $13(36.1)$ & $3(50.0)$ & $3(37.5)$ \\
\hline Veterans' health care & I (3.3) & $2(5.6)$ & $0(0.0)$ & $0(0.0)$ \\
\hline Uninsured & I (3.3) & $0(0.0)$ & $0(0.0)$ & $0(0.0)$ \\
\hline
\end{tabular}

Notes: ${ }^{a}$ Responses not mutually exclusive. ${ }^{b}$ Other race: Stage I AFib Latina $(n=I)$, Stage I OA Mix/Latin $(n=I)$; Stage 2 AFib Latina $(n=I) .{ }^{c}$ Other living conditions: Stage I OA rental home' $(n=I)$, Independent or retirement community $(I)$.

Abbreviations: AFib, atrial fibrillation; GED, General Educational Development; OA, osteoarthritis; SD, standard deviation. 
Table 3 Participant-Reported Clinical Characteristics

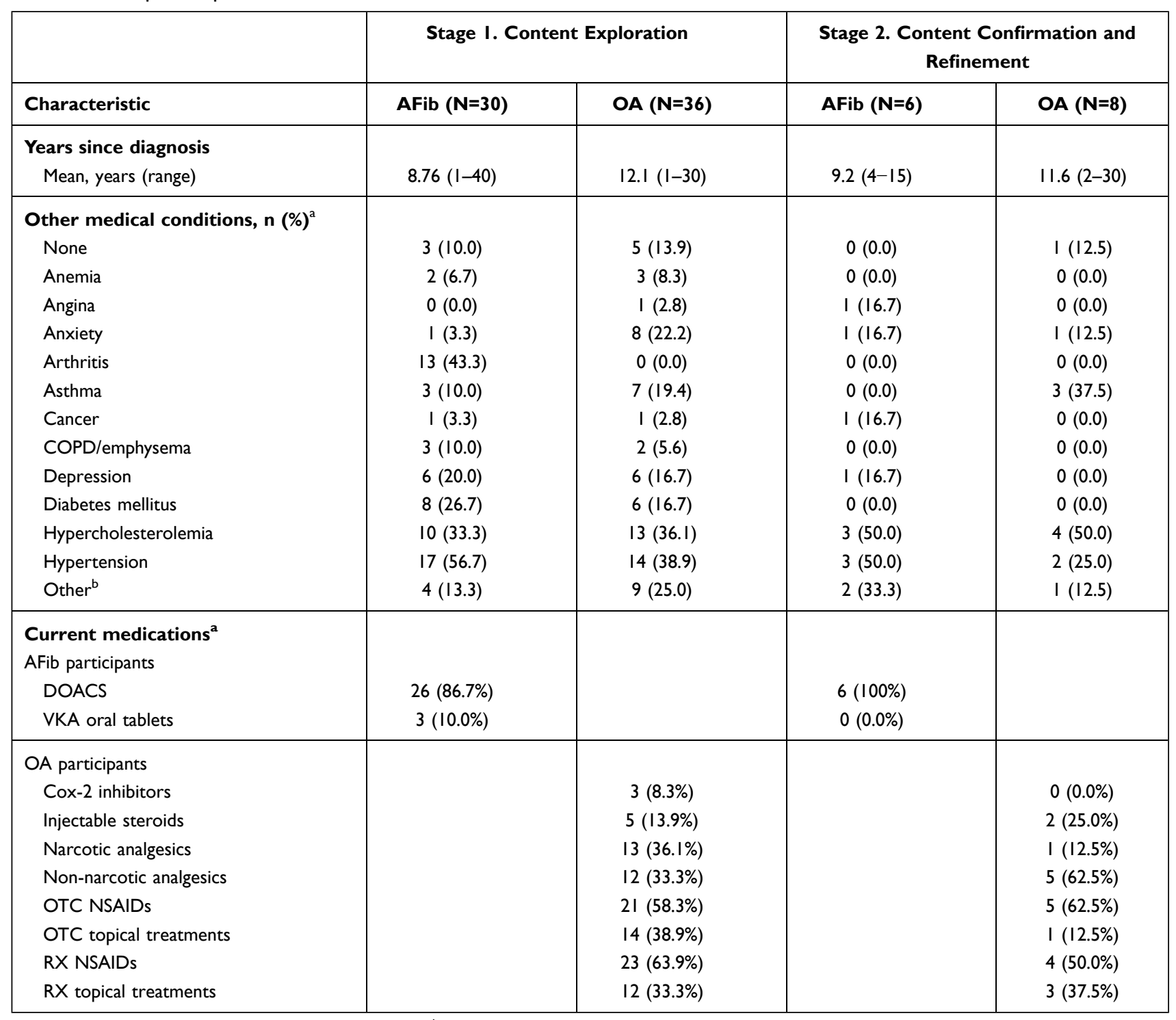

Notes: a As reported by participants; Not mutually exclusive. ${ }^{b}$ Other health conditions: Stage I AFib a-fib $($ sic; $n=2)$, Sjogren's $(n=I)$, sleep apnea $(n=I)$, osteopenia $(n=I)$ : Stage I OA Other health conditions: arthritis $(n=1)$, coronary artery disease $(n=1)$, fibromyalgia $(n=2)$, glaucoma $(n=1)$, knees $($ bone on bone; $n=1)$, osteoarthritis $(n=1)$, diverticulitis $(n=I)$, ulcerative colitis $(n=I)$, degenerative joint disease $(n=I)$, acute allergic rhinitis $(n=I)$, allergies $(n=I)$, shine/tendonitis/lumbar $($ low back pain; $n=I)$, hypothyroidism $(n=1)$, renal insufficiency $(n=1)$.

Abbreviations: COPD, chronic obstructive pulmonary disease; DOACS, direct oral anticoagulants; OTC, over-the-counter; RX, prescription; VKA, vitamin K antagonist.

(28\%; $n=10 / 36)$, inconvenience of twice-daily dosing/ application and affordability/insurance issues ( $6 \%$ each; $2 / 36)$. A few patients $(11 \% ; n=4 / 36)$ admitted stopping their OA medications altogether because of a sense of "toughing up." Many respondents had their own subjective "pain point" when they decided they needed an OA prescription medication. A few of the participants substituted their prescription drugs with OTC drugs, such as ibuprofen and acetaminophen, assuming the OTC drugs would have lesser side effects than their prescription medications for OA.
Participants used various "reminding devices" to help them with adherence, such as pill dispensers set every weekend, pill boxes, or social support systems such as spouses.

When participants were asked to prioritize OA against other chronic diseases they had, OA fell in the middle. Chronic diseases that ranked higher were hepatitis $\mathrm{C}$, diabetes, hypertension, congestive heart failure, and asthma. Participants expressed that $\mathrm{OA}$ becomes more important depending on the degree of pain and location of pain. 
Short- (eg, gastrointestinal upset and stomach problems) and long-term (eg, kidney and liver damage) side effects of OA medications were the top concern $(83 \% ; n=30 / 36)$. The next biggest concern was the potential of being addicted to their pain medications (39\%; $\mathrm{n}=14 / 36$ ). The third most common concern was the lack of efficacy ( $33 \% ; n=12 / 36)$. During three of the focus groups, participants raised inconvenience of dosing frequency as a factor in their medication adherence. While fear of addiction was common, some participants stockpiled narcotics "just in case it (the pain) gets too bad." Affordability was a concern for only a few participants (14\%; $\mathrm{n}=5 / 36)$.

The majority of participants expressed that their doctors were too busy and did not have time for all their concerns, but $47 \%(n=17 / 36)$ added that they still trusted them with their treatment decisions. Almost half of the participants had tried using turmeric, CBD oil, herbal teas, and glucosamine and chondroitin tablets as a complement to prescription therapy.

\section{Combined AFib and OA Focus Group Results}

Item stems covering 13 common concepts of interest (COIs) and 12 unique COIs were derived from the focus-group transcripts. The item stems and COIs were reviewed by the research team during an in-person meeting and COIs were either included or excluded from the draft medication adherence instrument depending on the extent to which they were viewed as modifiable, ie, the concept could be influenced through interventional education and other health management tools, such that there was a favorable impact on adherence. COIs deemed not to be modifiable were excluded. The team also discussed different wordings of items, recall period, and use of categorical response scales that would be appropriate for both AFib and OA populations at a sixth-grade reading level. The result was that $42 \mathrm{AFib}$ and $38 \mathrm{OA}$ items representing concepts relevant to factors that influence medication adherence and that were considered modifiable were drafted for further evaluation during cognitive debriefing.(Figure 5) These items were grouped into 8 common COIs, one COI specific to AFib and one specific to OA. A semistructured interview guide was also developed for use in the one-on-one interviews to confirm concept coverage and to probe various aspects of the item stems and response options that were included for each question, leading to final refinement of the items.

\section{Stage 2. Content Confirmation and Refinement \\ One-on-One Interviews}

In total, 14 hybrid interviews were conducted, 6 with persons with AFib and 8 with those having OA. Six participants ( 1 female and 5 males) were recruited in Boston, Massachusetts, US, and eight participants (4 females and 4 males) were recruited in Philadelphia, Pennsylvania. The demographic and clinical characteristics of these participants are shown in Tables 2 and 3.

\section{Cognitive Debriefing}

Almost half of all respondents (43.0\%) gave the questionnaire positive feedback, noting that it "seems sensible" and included "fundamental, important questions." Negative feedback ( $7 \%$ of respondents) was targeted at the length and redundancy of the questionnaire, which was somewhat expected as the purpose of the research was to test variations of the draft adherence assessment tool items. The remaining participants gave the questionnaire neutral feedback.

The response options in the medication adherence instrument ranged from "extremely ..." to 'not at all ..." and participants were asked to discuss how they perceived the differences among them. For many, there was a relationship between perceived risk and degree of concern. Participants demonstrated understanding of the differences between the response options and, in general, felt that there was a sufficient range of options.

For the set of questions about medication concerns, participants were asked "How concerned ...," "How worried ...," or "How afraid ..." they were about potential side effects. There was a preference for the word "concerned" in both groups $(67 \% ; n=4 / 6$ for AFib and $75 \%$ $n=6 / 8$ for OA). Four of the 5 participants who were asked about their preference for the term "side-effect" versus "adverse effects" preferred the term "side effects" ( 1 in the AFib group and all 3 in the OA group). Among a small sample of participants with OA, there was a preference for the term "medication" $(75 \% ; n=3 / 4)$ over "medicine" $(25 \% ; n=1 / 4)$.

When asked about the set of questions that was intended to assess how "concerned/worried/afraid" participants were about "bleeding" or "bruising" as sequelae of their AFib prescription medications, two participants $(50 \% ; n=2 / 4)$ stated they would prefer "bleeding" and "bruising" to remain separate while two participants $(50 \% ; n=2 / 4)$ reported they should be combined. The decision was made to retain these two concepts as separate 


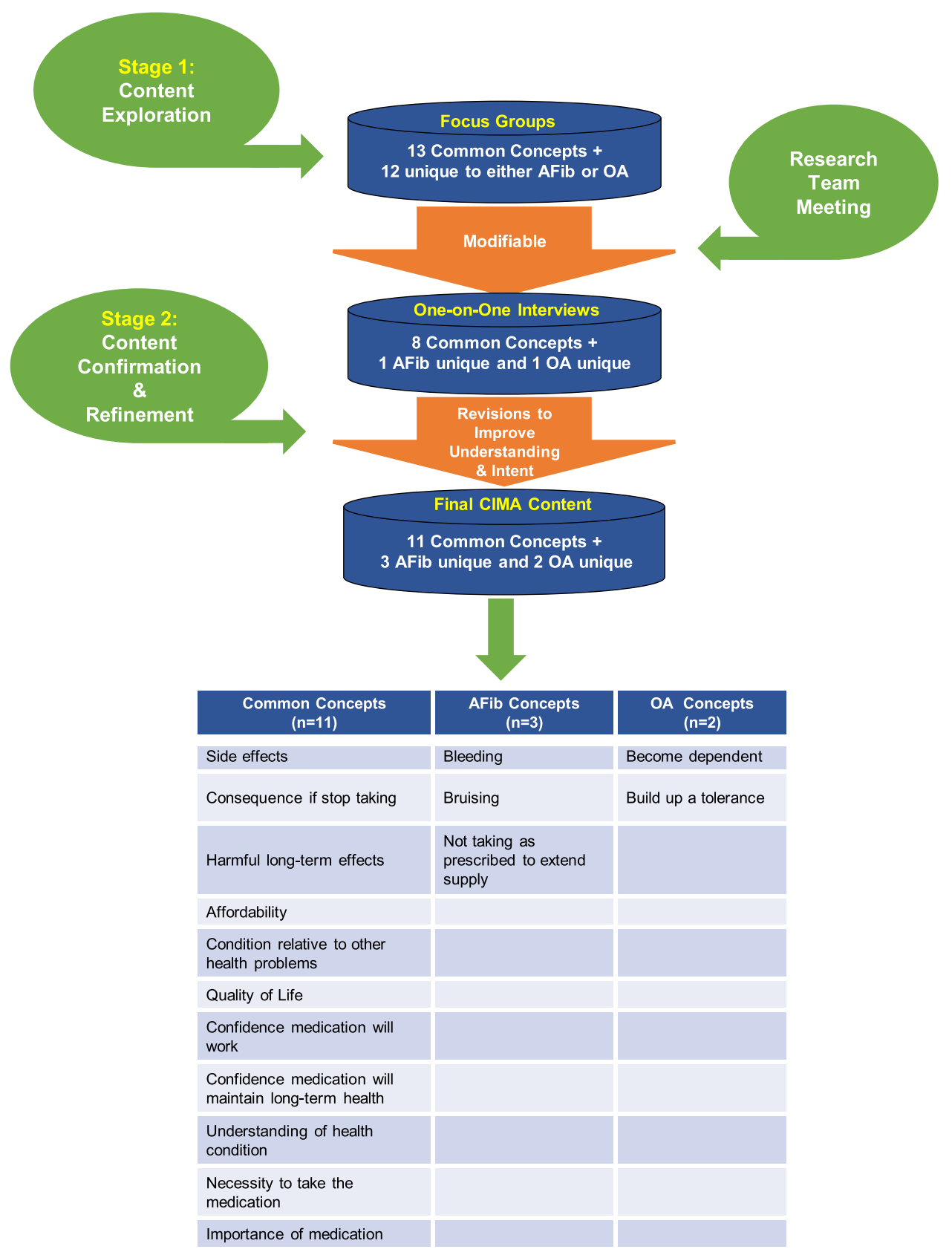

AFib, atrial fibrillation; CIMA, Concerns Influencing Medication Adherence; OA, osteoarthritis

Figure 5 CIMA content evolution.

items to distinguish between internal and external bleeding.

For the set of questions intended to assess "How concerned ...," "How motivated ...," "How convinced ...," "How necessary ...," "How essential ...," and/or "How confident ..." participants were when considering the importance of their medications, both AFib and OA participants reviewed eight different questions. Each question was worded in a slightly different way and offered five response options ranging from "Not at all ..." to "Extremely ..." The most preferred wording for the questions was "How necessary" (42.9\%; $n=6 / 14,3$ from each group). Two AFib participants $(33.3 \% ; n=2 / 6)$ and three OA participants $(37.5 \% ; n=3 / 8)$ reported that they preferred "How essential," while one AFib participant $(16.7 \% ; n=1 / 6)$ and 
three OA participants $(37.5 \% ; n=3 / 8)$ stated they preferred the term "convinced" over the other potential terms.

When asked about a set of five differently worded questions intended to assess "How concerned" and "How worried" participants were that their respective medication might have "harmful effects in the long term" or "longterm risks/effects," there was a general preference (78.5\%; $\mathrm{n}=11 / 14$ ) for the phrase "How concerned." This included 5 AFib participants $(83.3 \% ; n=5 / 6)$ and 6 OA participants $(75.0 \% ; n=6 / 8)$. Twelve participants were asked which wording they preferred among the following: "harmful effects in long-term," "harmful long-term effects," and "long-term risks to your health." Eight participants $(66.7 \% ; n=8 / 12)$ stated they preferred the term "harmful long-term effects;" $3(25 \% ; n=3 / 12)$ preferred "long-term risks," and $1(8.3 \% ; n=1 / 12)$ participant expressed preference for the term "harmful effects in long-term."

When asked to comment on a set of questions intended to assess "How confident ..." each participant was that their respective medication was "working for them," $33 \%$ $(n=2 / 6)$ of the AFib participants and $38 \%(n=3 / 8)$ of the OA participants preferred the word "confident" rather than "How concerned ...," "How sure ...," and "How convinced ...."

With respect to questions that assessed "How concerned ..." or "How worried" each participant was about "out of pocket costs" for their medications, 67\% $(n=4 / 6)$ of participants with AFib and $38 \%(n=3 / 8)$ of those with OA preferred the word "concerned" over the word "worried." The term "out of pocket" was also preferred, as it makes clear that the cost is a personal expense.

The next set of questions focused on the perceived importance of the participants' AFib or OA compared with other health problems they had. Four participants discussed the meaning of the term "future health." The lone participant with AFib said they associated the term "future health" with mortality, while the three OA participants had various interpretations. One thought the term was vague and could mean anything from "tonight to 10 years from now;" another thought of being "70, 80, or 90 years old;" and the third equated "future health" to "quality of life."

For the set of questions that was intended to assess how "concerned" each participant was about becoming addicted to or dependent on their OA medication, there was a general preference for "dependent." For the unique AFib questions about "missing" or "stretching out" doses of their oral anticoagulants, participants understood the terminology used. Participants made the distinction between missing doses and stretching out doses by explaining that missing doses is unintentional whereas stretching out doses is done willfully.

With respect to how "confident" the participants were in terms of their knowledge and understanding of their AFib or OA medication, there was a preference among those with AFib for the term "understanding" over "knowledge" (67\%; n=4/6).

Based on these findings, the final content for the Concerns Influencing Medication Adherence (CIMA) instrument includes 11 questions covering common COIs, 3 questions specific to AFib, and 2 questions specific to OA (Figure 5). Each question offers five possible responses ranging from "Not at all ..." to "Extremely ..."

\section{Discussion}

The objectives of this research were to develop a contentvalid, patient-reported assessment, the CIMA instrument, which is representative of the concerns that influence the decisions of persons living with AFib or OA regarding the filling and refilling of their prescription medications and can identify persons who are, or are likely to be, nonadherent to their medications (defined as failure to obtain the first prescribed refill and/or non-persistent after the first prescribed refill). This was accomplished through two stages of research: concept elicitation via focus groups to obtain direct patient input into the concepts that affect likelihood to fill and continue to refill prescription medications, and content confirmation and refinement via one-onone cognitive debriefing interviews to finalize the set of items that would represent a content valid assessment of medication adherence in these two patient populations. Concept saturation, an important criterion for establishing evidence that the concepts represented in an instrument are comprehensive and relevant to the intended responders (in this case patients) was achieved. Specifically, by the completion of five focus groups with individuals affected by AFib and six focus groups of individuals affected by OA, no new concepts emerged. Further, no concepts were introduced or mentioned as missing from the one-on-one interviews. After two rounds of cognitive debriefing interviews, no further refinements to the item stems and response scales were necessary, and interviewees understood that the time frame of reference for responding was "current" (ie, no past recall, rather "as of right now"). A recall period was not included in the draft medication 
adherence instrument used in the $\mathrm{CE} / \mathrm{CD}$ interviews to allow participants to think generally about their medication-taking experiences with the intent of making it more generalizable.

The CIMA instrument is intended to be completed electronically by patients. It is comprised of a core set of 11 items applicable to multiple disease states, as well as "add-on" items specific to persons with AFib (3 items) or OA ( 2 items). Use of the CIMA instrument is appropriate regardless of how patients obtain their prescriptions. It was designed to focus on intentional adherence, ie, active decisions on the part of patients to forego taking medication as prescribed. The context of use for the CIMA instrument is as a publicly available content-valid tool for use in population health management, by health plans, Integrated Delivery Networks (IDNs), and/or large group practices. A potential topic for future research is whether the CIMA instrument has practical applicability in clinical practice as a tool to help identify patients who might need additional intervention to stay adherent to their medication regimens.

This research has a few limitations. With respect to the literature review, differences in sampling strategies and sampling frames across the selected studies could have affected their representativeness and generalizability. All information on the clinical status of the focus group participants was based on self-report. The concepts of polypharmacy and pill burden came up sparingly in the qualitative research, and the participants did not raise the issue during the interviews. Thus, it is not addressed in the CIMA instrument. It is not unusual for persons with chronic illnesses to take multiple medications for a variety of medical conditions, however, and this may have been a factor (conscious or unconscious) in how the participants ranked their illnesses, and, therefore, their medications in terms of prioritization. This is a question that could be explored in future research. Both the focus groups and one-on-one interviews were conducted in coastal cities, as opposed to a broader sample that included persons from rural areas and/or from the Midwest or South. The sample populations for both OA and AFib were predominantly white and not of Hispanic origin. Similar to other research using opt-in chronic disease panels, ${ }^{46}$ participants in both the focus groups and oneon-one interviews were fairly highly educated.

The next steps for validating the CIMA instrument include usability testing in an electronic format, establishing a scoring algorithm, and evaluating its psychometric measurement performance, including identification of external criteria for evaluating its ability to identify those most likely and not likely to be adherent. The item stems used in this instrument were included depending on the extent to which they were viewed as modifiable, ie, the concept could be influenced through interventional education and other health management tools, such that there would be a higher likelihood of a favorable impact on adherence. These results need to be tested by fielding the CIMA instrument in a future research study and examining of the effects of said interventions. Finally, for use in conditions outside of AFib or OA, we recommend additional qualitative research to confirm that the core items are relevant and to identify any COIs that are unique to other patient population or conditions of interest.

\section{Conclusion}

While a variety of instruments have been developed on medication adherence, many lack publicly available details concerning patient input. The current research collects direct patient input, a key component of content validity, that centers on identifying concerns that patients have regarding their treatments. Such concerns are expected to have affected past medication adherence and can potentially impact future adherence. Our focus was on active (and thus potentially modifiable) decisions on the part of patients to forego taking medications as prescribed. The proposed tool is intended to be completed electronically, to be publicly available for licensing, and to constitute a core set of general and specific items applicable to persons with AFib or OA. Although applicability outside of either AFib or OA was not assessed, the general items may be useful in assessing adherence in other chronic diseases.

\section{Abbreviations}

AFib, atrial fibrillation; CD, cognitive debriefing; $\mathrm{CE}$, concept elicitation; CIMA, Concerns Influencing Medication Adherence; COI, concept of interest; DOACs, direct-acting oral anticoagulants; FDA, United States Food and Drug Administration; GED, General Educational Development; INR, international normalized ratio; IRB, Institutional Review Board; NSAID, nonsteroidal anti-inflammatory drug; OA, osteoarthritis; OTC, over-the-counter; PRISMA, Preferred Reporting Items for Systematic Reviews and Meta-Analyses; PRN, pro re nata; as needed; PRO, patient-reported-outcomes; SD, standard deviation; US, United States; VKA, vitamin-K antagonist. 


\section{Acknowledgments}

The authors were saddened to learn of the passing of Dr Colleen McHorney in January 2021. Dr McHorney served as primary investigator of this research and contributed to the development of the protocols, the conduct of the research, and the preparation of the final study reports. We acknowledge the individuals who participated in this research. Patient recruitment was conducted by The Schlesinger Group using their own proprietary database and/or access to partner databases. Writing and editorial assistance was provided by Maria B. Vinall of Medical Communications Depot, Inc. Ms Vinall's services were paid for by Pfizer, which sponsored this research.

\section{Disclosure}

Elizabeth A MacLean, Laura L Manzey, Carl J Possidente, Joseph C Cappelleri, and Linda S Deal are employed by Pfizer, Inc (the study sponsor) and have received stock as part of their compensation. At the time of the study, Sonal Ghura Mansukhani was employed by Evidera, which collaborated on the study. She is now employed by Takeda. The authors report no other conflicts of interest in this work.

\section{References}

1. Cea-Calvo L, Marín-Jiménez I, de Toro J, et al. Different associations of intentional and non-intentional non-adherence behaviors with patient experience with healthcare and patient beliefs in medications: a survey of patients with chronic conditions. Patient Prefer Adherence. 2020;14:2439-2450. doi:10.2147/PPA.S281985

2. Margolis Center. Medication adherence: landscape, strategies, and evaluation methods: meeting summary. 2019; Available from: https:// healthpolicy.duke.edu/sites/default/files/2020-07/Medication $\%$ 20Adherence_Public\%20Meeting\%20Summary.pdf. Accessed 3 December, 2020.

3. Lam WY, Fresco P. Medication adherence measures: an overview. Biomed Res Int. 2015;2015:217047. doi:10.1155/2015/217047

4. Osterberg L, Blaschke T. Adherence to medication. $N$ Engl J Med. 2005;353(5):487-497. doi:10.1056/NEJMra050100

5. Benjamin RM. Medication adherence: helping patients take their medicines as directed. Public Health Rep. 2012;127(1):2-3. doi:10.1177/ 003335491212700102

6. Pellegrin KL, Lee E, Uyeno R, Ayson C, Goo R. Potentially preventable medication-related hospitalizations: a clinical pharmacist approach to assessment, categorization, and quality improvement. $J$ Am Pharm Assoc (2003). 2017;57(6):711-716. doi:10.1016/j. japh.2017.06.019

7. DiMatteo MR. Variations in patients' adherence to medical recommendations: a quantitative review of 50 years of research. Med Care. 2004;42(3):200-209. doi:10.1097/01.mlr.0000114908.90348.f9

8. World Health Organization. Adherence to long-term therapies: evidence for action. 2003; Available from: https://www.who.int/chp/ knowledge/publications/adherence_full_report.pdf?ua $=1$. Accessed 3 December, 2020.

9. Kvarnström K, Airaksinen M, Liira H. Barriers and facilitators to medication adherence: a qualitative study with general practitioners. BMJ Open. 2018;8(1):e015332. doi:10.1136/bmjopen-2016-015332
10. Food and Drug Administration. Guidance for Industry patient-reported outcome measures: use in medical product development to support labeling claims. 2009; Available from: http://www. fda.gov/downloads/Drugs/Guidances/UCM193282.pdf. Accessed December 8, 2020.

11. FDA. FDA patient-focused drug development guidance series for enhancing the incorporation of the patient's voice in medical product development and regulatory decision making. 2020; Available from: https://www.fda.gov/drugs/development-approval-process-drugs/fdapatient-focused-drug-development-guidance-series-enhancingincorporation-patients-voice-medical. Accessed 18 February, 2020.

12. Moher D, Shamseer L, Clarke M, et al. Preferred reporting items for systematic review and meta-analysis protocols (PRISMA-P) 2015 statement. Syst Rev. 2015;4(1):1. doi:10.1186/2046-4053-4-1

13. Liberati A, Altman DG, Tetzlaff J, et al. The PRISMA statement for reporting systematic reviews and meta-analyses of studies that evaluate healthcare interventions: explanation and elaboration. BMJ. 2009;339:b2700. doi:10.1136/bmj.b2700

14. Popay J, Roberts H, Sowden A, et al. Guidance on the conduct of narrative synthesis in systematic reviews. A product from the ESRC methods programme Version; 2006. Available form: http://citeseerx. ist.psu.edu/viewdoc/download?doi=10.1.1.178.3100\&rep= rep1\&type=pdf. Accessed December 8, 2020.

15. Bajorek B, Saxton B, Anderson E, Chow CK. Patients' preferences for new versus old anticoagulants: a mixed-method vignette-based study. Eur J Cardiovasc Nurs. 2018;17(5):429-438. doi:10.1177/ 1474515117739618

16. Barrett AD, DiBeneditti D, Phatak H, Masseria C, Kamble S. Focus groups exploring experiences with and preferences for oral anticoagulants in people with nonvalvular atrial fibrillation. Abstract PCV68 Presented at the 21st Annual meeting of the International Society for Pharmacoeconomic and Outcomes Research 21-25 May, Washington, DC, USA. Value Health. 2016;19(3):A51.

17. Bartoli-Abdou JK, Patel JP, Crawshaw J, et al. Exploration of adherence and patient experiences with DOACs one year after switching from vitamin-K antagonists- insights from the switching study. Thromb Res. 2018;162:62-68. doi:10.1016/j. thromres.2017.12.021

18. Clarkesmith DE, Lip GYH, Lane DA. Patients' experiences of atrial fibrillation and non-vitamin $\mathrm{K}$ antagonist oral anticoagulants (NOACs), and their educational needs: a qualitative study. Thromb Res. 2017;153:19-27. doi:10.1016/j.thromres.2017.03.002

19. Ferguson C, Inglis SC, Newton PJ, Middleton S, Macdonald PS, Davidson PM. Barriers and enablers to adherence to anticoagulation in heart failure with atrial fibrillation: patient and provider perspectives. J Clin Nurs. 2017;26(23-24):4325-4334. doi:10.1111/ jocn. 13759

20. Gumbinger C, Holstein T, Stock C, Rizos T, Horstmann S, Veltkamp R. Reasons underlying non-adherence to and discontinuation of anticoagulation in secondary stroke prevention among patients with atrial fibrillation. Eur Neurol. 2015;73(3-4):184-191. doi:10.1159/000371574

21. Mas Dalmau G, Sant Arderiu E, Enfedaque Montes MB, Solà I, Pequeño Saco S, Alonso Coello P. Patients' and physicians' perceptions and attitudes about oral anticoagulation and atrial fibrillation: a qualitative systematic review. BMC Fam Pract. 2017;18(1):3. doi:10.1186/s12875-016-0574-0

22. Müller S, Kohlmann T, Wilke T. Validation of the Adherence Barriers Questionnaire - an instrument for identifying potential risk factors associated with medication-related non-adherence. BMC Health Serv Res. 2015;15:153. doi:10.1186/s12913-015-0809-0

23. Pandya EY, Bajorek B. Factors Affecting Patients' Perception On, and Adherence To, Anticoagulant Therapy: anticipating the Role of Direct Oral Anticoagulants. The Patient. 2017;10(2):163-185. doi:10.1007/s40271-016-0180-1 
24. Ruiz MA, González-Porras JR, Aranguren JL, et al. Development and validation of a new questionnaire measuring treatment satisfaction in patients with non-valvular atrial fibrillation: $\operatorname{SAFUCA}\left({ }^{\circledR}\right)$. Qual Life Res. 2017;26(3):767-778. doi:10.1007/s11136-016-1474-4

25. Vaanholt MC, Weernink MG, Jzerman MJ, von Birgelen C, van Til JA. A qualitative exploration of reasons for (non-)adherence to oral anticoagulant therapy in patients with atrial fibrillation. Abstract PCV110 presented at the 20TH International Society for Pharmacoeconomic and Outcomes Research (ISPOR) Annual European Congress, 4-8 November Glasgow, Scotland, UK. Value Health. 2017;20(9):A620.

26. Vaanholt MCW, Weernink MGM, von Birgelen C. Perceived advantages and disadvantages of oral anticoagulants, and the trade-offs patients make in choosing anticoagulant therapy and adhering to their drug regimen. Patient Educ Couns. 2018;101(11):1982-1989. doi:10.1016/j.pec.2018.06.019

27. Weernink MGM, Vaanholt MCW, Groothuis-Oudshoorn CGM, von Birgelen C. Patients' Priorities for Oral Anticoagulation Therapy in Non-valvular Atrial Fibrillation: a Multi-criteria Decision Analysis. Am J Cardiovasc Drugs. 2018;18(6):493-502. doi:10.1007/s40256018-0293-0

28. Alami S, Boutron I, Desjeux D, et al. Patients' and practitioners' views of knee osteoarthritis and its management: a qualitative interview study. PLoS One. 2011;6(5):e19634. doi:10.1371/journal. pone.0019634

29. Carpenter D, Blalock S, DeVellis R. Conflicting medication information is associated with worse medication adherence. Abstract P169 Presented at the Society for Clinical and Translational Science Annual Meeting 18-20 April, Washington, DC, USA. Clin Transl Sci. 2012;5(2):29.

30. Dockerty T, Latham SK, Smith TO. Why don't patients take their analgesics? A meta-ethnography assessing the perceptions of medication adherence in patients with osteoarthritis. Rheumatol Int. 2016;36(5):731-739. doi:10.1007/s00296-016-3457-8

31. Geryk LL, Blalock S, DeVellis RF, Morella K, Carpenter DM. Associations between patient characteristics and the amount of arthritis medication information patients receive. J Health Commun 2016;21(10):1122-1130. doi:10.1080/10810730.2016.1222036

32. Geryk LL, Blalock SJ, DeVellis RF, Jordan JM, Han PK, Carpenter DM. Medication-related self-management behaviors among arthritis patients: does attentional coping style matter? Open Rheumatol J. 2016;10:60-70. doi:10.2174/1874312901610010060

33. Laba TL, Brien JA, Fransen M, Jan S. Patient preferences for adherence to treatment for osteoarthritis: the MEdication Decisions in Osteoarthritis Study (MEDOS). BMC Musculoskelet Disord. 2013;14:160. doi:10.1186/1471-2474-14-160

34. Manias E, Claydon-Platt K, McColl GJ, Bucknall TK, Brand CA. Managing complex medication regimens: perspectives of consumers with osteoarthritis and healthcare professionals. Ann Pharmacother. 2007;41(5):764-771. doi:10.1345/aph.1H623
35. Myung G, Harada ND, Fong SL, Aquino-Beaton C, Fang MA. Characterization of social stigma in rheumatic diseases and correlation with quality of life and medication adherence. Abstract 2107 Presented at the 2014 ACR/ARHP Annual Meeting 14-19 November, Boston, MA, USA. Arthritis Rheumatol. 2014;66(10):S921.

36. Pouli N, Das Nair R, Lincoln NB, Walsh D. The experience of living with knee osteoarthritis: exploring illness and treatment beliefs through thematic analysis. Disabil Rehabil. 2014;36(7):600-607. doi:10.3109/09638288.2013.805257

37. Sale JE, Gignac M, Hawker G. How "bad" does the pain have to be? A qualitative study examining adherence to pain medication in older adults with osteoarthritis. Arthritis Rheum. 2006;55(2):272-278. doi:10.1002/art.21853

38. Selten EM, Vriezekolk JE, Geenen R, et al. Reasons for treatment choices in knee and hip osteoarthritis: a qualitative study. Arthritis Care Res. 2016;68(9):1260-1267. doi:10.1002/acr.22841

39. Warner LM, Schüz B, Aiken L, et al. Interactive effects of social support and social conflict on medication adherence in multimorbid older adults. Soc Sci Med. 2013;87:23-30. doi:10.1016/j. socscimed.2013.03.012

40. Wiederkehr S, De Bock E, Chekroun M, Arnould B. Adherence issues in osteoarthritis: how can acceptance measurement help understanding patients' concerns and working on solutions? Abstract PMS46 presented at the International SOciety for Pharmacoeconomics and Outcomes research (ISPOR) Real-World, Digital Health, and the New Landscape for Health Decisions Making Conference 19-23 May, Baltimore, MD, USA. Value Health. 2018;21:S198-S199.

41. Thomas J, Harden A. Methods for the thematic synthesis of qualitative research in systematic reviews. BMC Med Res Methodol. 2008;8:45. doi:10.1186/1471-2288-8-45

42. McHorney CA, Bricker DE, Kramer AE, et al. The SWAL-QOL outcomes tool for oropharyngeal dysphagia in adults: I. Conceptual foundation and item development. Dysphagia. 2000;15(3):115-121. doi: $10.1007 / \mathrm{s} 004550010012$

43. van Someren MW, Barnard Y, Sandberg J. The Think Aloud Method: A Practical Guide to Modelling Cognitive Processes. London, United Kingdom: Academic Press; 1994.

44. Braun V, Clarke V. Using thematic analysis in psychology. Qual Res Psychol. 2006;3:77-101. doi:10.1191/1478088706qp063oa

45. Muhr T. User's Manual for ATLAS.ti 5.0, ATLAS.ti Scientific Software Development. Berlin, Germany: Scientific Software Development GmbH; 2004.

46. McHorney CA. The Adherence Estimator: a brief, proximal screener for patient propensity to adhere to prescription medications for chronic disease. Curr Med Res Opin. 2009;25(1):215-238. doi:10.1185/03007990802619425
Patient Preference and Adherence

\section{Publish your work in this journal}

Patient Preference and Adherence is an international, peer-reviewed, open access journal that focusing on the growing importance of patient preference and adherence throughout the therapeutic continuum. Patient satisfaction, acceptability, quality of life, compliance, persistence and their role in developing new therapeutic modalities and compounds to optimize clinical outcomes for existing disease states are major areas of interest for the journal. This journal has been accepted for indexing on PubMed Central. The manuscript management system is completely online and includes a very quick and fair peer-review system, which is all easy to use. Visit http:// www.dovepress.com/testimonials.php to read real quotes from published authors. 